\title{
Gestão de Informações Pessoais (PIM) em perspectiva: contribuições para o tratamento de arquivos pessoais digitais
}

\author{
Perspective Personal Information Management (PIM): Contributions to the handling of \\ digital personal archives
}

\author{
Jorge Phelipe Lira de Abreu \\ Mestre em Gestão de Documentos e Arquivos \\ Universidade Federal do Estado do Rio de Janeiro \\ j.phelipeabreu@gmail.com \\ Aline Lopes de Lacerda \\ Doutora em História Social \\ Universidade de São Paulo \\ aline.lacerda@fiocruz.br \\ Luciana Quillet Heymann \\ Doutora em Sociologia \\ Instituto Universitário de Pesquisas do Rio de Janeiro \\ luciana.heymann@fiocruz.br
}

\section{Resumo}

Apresenta os estudos em Gestão de Informações Pessoais (PIM) como indicadores de comportamento na criação, manutenção, avaliação, seleção e preservação de arquivos pessoais digitais, bem como esses estudos podem contribuir para o tratamento desses arquivos.

\section{Palavras-chave}

Arquivo pessoal digital. Preservação digital. Documento digital.

\begin{abstract}
It presents studies on Personal Information Management (PIM) as behavioral indicators in the creation, maintenance, evaluation, selection and preservation of digital personal archives, as well as these studies can contribute to the treatment of these archives.
\end{abstract}

\section{Keywords}

Digital personal archive. Digital preservation. Digital record.

\section{INTRODUÇÃO}

Nos documentos produzidos por um indivíduo no âmbito doméstico consta o que Lansdale $\left(2006\right.$, p. 55) chama de informação ${ }^{1}$ pessoal, não com a conotação de que sejam

\footnotetext{
${ }^{1}$ Para efeitos deste trabalho considera-se informação "todo e qualquer elemento referencial contido num documento" (CAMARGO; BELLOTTO, 1996, p. 44). Portanto, quando se utiliza o termo informação, pressupõese que ela esteja registrada em um documento.
} 
informações privadas, mas de que são mantidas para o próprio uso do indivíduo. Bass (2013, p. 52) afirma que diversos trabalhos mencionam Lansdale como o primeiro autor a abordar a gestão de informações pessoais como uma prática e área de estudo. Segundo Jones e Teevan (apud BASS, 2013, p. 51, tradução nossa) a PIM é

\begin{abstract}
Tanto a prática como o estudo das atividades que as pessoas realizam para adquirir, organizar, manter, recuperar, usar e controlar a distribuição de itens de informação, como documentos (papel e digital), páginas da Web e mensagens de e-mail para uso diário para completar tarefas (relacionadas ao trabalho ou não) e cumprir os vários papéis de uma pessoa (como pai, empregado, amigo, membro da comunidade, etc.).
\end{abstract}

Como área de estudo, a gestão de informações pessoais "baseia-se no melhor trabalho de uma variedade de disciplinas, incluindo psicologia cognitiva, interação homemcomputador, gestão de banco de dados, recuperação de informações e ciência da informação" (JONES apud BASS, 2013, p. 51, tradução nossa). Segundo Bass (2013, p. 51-52), os estudos de gestão de informações pessoais são realizados a fim de encontrar novas formas para contribuir com o gerenciamento de grandes volumes de informação em meio digital com agilidade e eficácia por meio do desenvolvimento de hardware e software, como gerenciadores de texto, de e-mail, de imagem e de música, navegadores, calendários, entre outros aplicativos.

Nesse sentido, os estudos são conduzidos, em sua maioria, pela lógica comercial, sem necessariamente contemplar uma abordagem arquivística. Bass (2013, p. 5) afirma que todas as tecnologias de gestão de informações pessoais contemplam três funções primárias: criar, organizar e (re)acessar informações no que o autor chama de "coleções digitais pessoais". Entretanto, quando contam com uma abordagem arquivística, os estudos de tecnologia de PIM recebem uma quarta função, a preservação em longo prazo de informações pessoais digitais. Segundo John et al. (2010, tradução nossa):

\footnotetext{
Espera-se que a Gestão de Informações Pessoais (PIM) eficaz, versátil e robusta surja no tempo, à medida que a demanda por manuseio eficiente de informações pessoais se incrementa; mas no momento uma tal capacidade abrangente está muito ausente. Há uma necessidade específica de promover uma forma de PIM orientada por uma abordagem arquivística que abranja todo o ciclo de vida da informação e seja direcionada para garantir autênticos objetos digitais pessoais e torná-los prontamente disponíveis para uso e reuso dos indivíduos produtores e proprietários para além do futuro imediato.
}

Portanto, essa produção que se dedica aos estudos de comportamento de usuário para desenvolvimento de tecnologias de gestão de informações pessoais e que se dá, de um modo geral, fora do âmbito das publicações arquivísticas permite vislumbrar o cenário e a dinâmica de criação e uso dos documentos pessoais digitais, antes de ingressarem nas instituições de custódia, fornecendo informações técnicas e contextuais fundamentais para o tratamento arquivístico desses conjuntos documentais. A seguir, explora-se, a partir da perspectiva PIM, a criação e manutenção de documentos pessoais digitais, os critérios de valoração e os hábitos de preservação dos produtores.

\title{
2 CRIAÇÃO E MANUTENÇÃO DE ARQUIVOS PESSOAIS DIGITAIS
}

Uma pessoa documenta espontaneamente, durante a vida, em sua rotina diária, atividades públicas e privadas. Oriundos das necessidades mais diversas, os documentos que 
compõem um arquivo pessoal são produzidos, em sua maioria, sem preparo ou por objetivos experimentais. Com o desenvolvimento e popularização das tecnologias, indivíduos se comunicam e operam financeiramente por meio eletrônico, fazem fotos e vídeos digitais, administram perfis em redes sociais, entre uma ampla gama de outras operações digitais das quais os documentos constituem evidência. Esse instante do registro da atividade em um documento consiste na gênese documental no ambiente pessoal e os documentos ainda não passaram por designações de valor, gestão ou preservação por parte do produtor.

Bass (2013, p. 54), ao apresentar como os documentos pessoais digitais são produzidos, esclarece que quando a documentação assume a forma digital ela se constitui como um tipo de arquivo específico. Kirschenbaum (apud BASS, 2012, p. 53, tradução nossa) exemplifica:

Quando um indivíduo está criando um documento do Microsoft Word, os dados são alocados para memória de acesso aleatório (RAM) até que um comando de salvamento automático ou salvamento manual é executado, momento em que os dados são codificados para um algoritmo de formatação exclusivo, atribuído um sufixo com uma extensão de três ou quatro caracteres (.doc ou .docx) e armazenado na unidade de disco rígido (HD).

Os sistemas operacionais usam essas extensões de arquivo para localizar e executar o programa associado necessário para tornar a cadeia de bits legível aos humanos (BASS, 2013 , p. 54). Atualmente o PRONOM ${ }^{2}$ possui cerca de 1.494 formatos de arquivos identificados. Os formatos podem ser classificados em duas categorias: arquivos produzidos off-line, análogos a formulários analógicos, e arquivos on-line, usados exclusivamente na construção de conteúdo baseado na web (BASS, 2013, p. 53). Tanto os arquivos produzidos off-line quanto os arquivos produzidos on-line dependem de programas associados para que sejam acessados. Nesse sentido, o formato de arquivo é parte fundamental do documento digital pessoal.

Outro aspecto fundamental dos arquivos pessoais digitais é que o computador pessoal se constitui no domínio comum em que os documentos são criados, manipulados e armazenados. Mesmo com a proliferação de equipamentos e dispositivos, os usuários concentram seus documentos no computador. As fotografias feitas por sua câmera digital eram acessadas e processadas por programa específico instalado em computador, da mesma maneira que as músicas digitais adquiridas, os vídeos e textos compartilhados em blogs e redes sociais, estavam todos baseados no computador. Desse modo, "o computador pessoal tem atuado há algum tempo como uma central para a produção de arquivos digitais, bem como seu uso contínuo e gestão no que pode ser referido como uma série de ações de manutenção de documentos." (BASS, 2013, p. 54, tradução nossa). O autor afirma que

Todos os computadores pessoais oferecem a capacidade de criar pastas por meio de aplicativos de gerenciamentos de arquivos (Windows Explorer ou Mac Finder) para organizar texto, áudio, vídeo, planilhas e apresentações dinâmicas, entre outras categorias de arquivos. Essas pastas são, por sua vez, agrupadas hierarquicamente para criar estruturas profundas ou superficiais contendo centenas, senão milhares, de itens digitais agregados. Como os computadores pessoais são frequen-

\footnotetext{
${ }^{2}$ O PRONOM é uma base de dados técnica on-line para apoiar serviços de preservação digital, desenvolvido pelo Arquivo Nacional do Reino Unido. Configura-se como um recurso para qualquer pessoa que necessite obter informações sobre os formatos de arquivo, produtos de software e outros componentes técnicos necessários para suportar o acesso em longo prazo a documentos e outros objetos digitais de valor cultural, histórico ou comercial.
} 
temente o centro de criação e organização, o gerenciamento de arquivos é um componente central da manutenção pessoal de documentos. (BASS, 2013, p. 54, tradução nossa).

O segundo centro de manutenção de documentos pessoais digitais identificado por Bass (2013, p. 55) é o e-mail. Adotado como substituto da correspondência manuscrita e datiloscrita, por sua disponibilidade e interface amigável, o e-mail é o meio de comunicação digital mais disseminado no âmbito profissional e pessoal (SCERRI; HANDSCHUH; DECKER apud BASS, 2013, p. 56). Atualmente o e-mail divide sua aderência com os aplicativos de mensagens instantâneas (Whatsapp e Messenger). Segundo Ducheneaut e Bellotti (apud BASS, 2013, p. 56), como a correspondência escrita, o e-mail é uma manifestação gravada de comunicação assíncrona entre duas ou mais pessoas e é, em muitos aspectos, o principal meio de comunicação não presencial no início do século XXI.

Entretanto, o e-mail tem sido usado para além de sua função de comunicação. Associado a calendários eletrônicos, o e-mail tem sido utilizado no gerenciamento de tarefas, bem como para o compartilhamento e arquivamento de documentos. Segundo Whittaker, Bellotti e Gwizdka (apud BASS, 2013, p. 56, tradução nossa), "como um aplicativo PIM, o email cresceu para abranger as funções de manutenção de documentos pessoais a tal ponto que muitas pessoas 'tendem a viver em e-mail', como demonstrado pela enorme quantidade de tempo gasto ao usá-lo."

Henderson (apud BASS, 2013, p. 56) identifica alguns padrões na manutenção de documentos pessoais digitais. No primeiro - chamado pela autora de estratégia de arquivamento - os usuários desenvolvem estruturas razoáveis de pastas através de limpezas frequentes ou quando o volume de documentos as justificam. Como a estrutura de pastas é de profundidade média, a navegação pela estrutura é utilizada para localizar documentos ao invés da busca por termo.

O segundo padrão constatado - empilhamento - envolve agrupamentos de documentos parcialmente desorganizados para os quais se constrói uma estrutura pequena de pastas que é utilizada sem disciplina. Nesse caso, a área de trabalho do computador é a principal área de organização e, portanto, pode ser navegada com relativa facilidade, enquanto os documentos são recuperados pela consulta de termos.

O último padrão identificado por Henderson sugere uma estratégia ideal e que pode ser estimulada durante a pré-custódia - estruturação - demonstra um arcabouço organizado de pastas com poucos documentos sem classificação. Os usuários, em alguns casos, direcionam a produção de documentos por meio da criação de categorias de pastas com antecedência. $\mathrm{O}$ acesso aos documentos, nessa estratégia, depende do contexto de organização, como uma hierarquia de pastas, para localizar informações dentro de sua estrutura de pastas.

Em seus estudos sobre a maneira como os usuários organizam e localizam arquivos em seus computadores, Barreau e Nardi (1995, p. 40-41) identificaram duas maneiras básicas para encontrar arquivos: uma baseada na localização (estrutura de pastas) e outra lógica (busca textual). A escolha depende, segundo os autores, do tipo de informação que eles estão trabalhando, que podem ser "informação efêmera", "informação de trabalho" e "informação arquivada".

As informações efêmeras são de uso corrente e têm vida útil curta, como mensagens eletrônicas, listas de afazeres, blocos de notas e notícias capturadas. A questão que permeia as informações efêmeras diz respeito a onde e como armazenar informações utilizadas por um curto período de tempo, uma vez que há um limite de documentos que podem constar 
na área de trabalho. As informações de trabalho são aquelas úteis para o trabalho atual do usuário e têm vida útil um pouco menos curta que a das informações efêmeras. Normalmente são importantes a ponto de serem organizadas por localização em categorias de pastas ou na área de trabalho. As informações arquivadas têm vida útil maior e são importantes para além do seu valor para os trabalhos atuais do usuário. Dizem respeito a trabalhos concluídos, como relatórios e históricos de projetos. Essas informações não costumam ser organizadas por requerer mais tempo e esforço do usuário, a sua recuperação se dá por busca textual e não por localização (BARREAU; NARDI, 1995, p. 41-42). Nesse sentido, identifica-se que a organização dos documentos nos computadores pessoais é determinada pelo tipo de uso que os indivíduos fazem desses documentos. Entretanto, essa classificação pode ter fronteiras tênues e os três tipos de informação conviverem no mesmo diretório. No mesmo espaço, o usuário pode armazenar informações "efêmeras", "de trabalho" e "arquivadas", sem distinção.

Voltando ao uso de correio eletrônico, Mackay (1988), em sua pesquisa sobre as maneiras pelas quais os profissionais de escritório usam o correio eletrônico para gerenciar seu trabalho diário, identificou que o correio eletrônico é mais do que apenas um sistema de comunicação.

\begin{abstract}
Além de apoiar o gerenciamento de informações, ele fornece um mecanismo para suportar uma variedade de atividades de gerenciamento de tempo e gerenciamento de tarefas. Algumas pessoas são priorizadoras, concentrando-se no problema de gerenciar mensagens recebidas. Outros são arquivadores, concentrando-se em como arquivar informações para uso subsequente. Da mesma forma, algumas pessoas usam o correio para delegar tarefas, enquanto outras executam tarefas delegadas a elas por outros eletronicamente. (MACKAY, 1988, p. 344, tradução nossa).
\end{abstract}

Mackay (1988, p. 350) identificou algumas formas principais de uso do e-mail: para gestão de tempo, gestão de tarefas e gestão de informações. Os usuários que lidam com o $e$ mail como uma ferramenta para gerir tempo, chamados priorizadores, se interessam em identificar e privilegiar mensagens importantes. Os solicitadores e performers são os usuários que usam o e-mail para gerenciar tarefas e se importam em delegar tarefas a quem tem capacidade de executá-las da melhor maneira. Por fim, aqueles que utilizam o e-mail para gerenciar informações, os chamados arquivadores, se dedicam à classificação e recuperação de mensagens. Os arquivadores não têm hábito de eliminar mensagens. "O estudo de Mackay revela como os padrões de organização de e-mail dos indivíduos são influenciados por como eles pensam sobre as funções do e-mail." (BASS, 2013, p. 58, tradução nossa).

O uso do e-mail para além da sua função primária de comunicação também foi identificado por Whittaker e Sidner (1996, p. 276, tradução nossa). O e-mail "agora está sendo usado para funções adicionais para as quais não foi projetado, como gerenciamento de tarefas e arquivamento pessoal. Chamamos isso de sobrecarga de e-mail." Os autores identificaram as principais funções para o e-mail na população estudada: gestão de tarefas, arquivamento pessoal e comunicação assíncrona (WHITTAKER; SIDNER, 1996, p. 276).

Na gestão de tarefas, os usuários desejam que as informações estejam prontamente disponíveis, para que o contexto das tarefas seja preservado e seja possível determinar o progresso das tarefas em andamento. Nesse caso, o e-mail é utilizado também para lembrar ações a serem tomadas. Na função de arquivamento pessoal, as informações são organizadas e classificadas para acesso em longo prazo. Segundo os autores, os usuários têm problema na criação de rótulos apropriados para as pastas ao arquivar informações para uso 
futuro. O uso do e-mail como meio de comunicação assíncrona preocupa-se com a interação no espaço e no tempo (WHITTAKER; SIDNER, 1996, p. 276).

Em estudo sobre PIM, Boardman e Sasse (2004, p. 589) concluem que as estratégias de gestão variam entre ferramentas e que o valor da informação influencia a seleção da estratégia. Os usuários sentem um senso de propriedade sobre os documentos nos quais investiram tempo na criação e, por isso, se dispõem a organizá-los. A estratégia de organização é definida a partir da probabilidade e estilo de recuperação dos documentos. Segundo os autores "os usuários percebem que a organização de arquivos é mais valiosa, já que o custo de arquivamento é compensado pelos benefícios previstos em tempo de recuperação." (BOARDMAN; SASSE, 2004, p. 589, tradução nossa). Os autores identificaram que, no e-mail, os usuários tendem a organizar menos as mensagens, já que localizam as mensagens por meio de metadados como autor e data das mensagens. O modo de aquisição dos documentos influencia também na organização. Documentos são criados gradualmente enquanto e-mails se acumulam de maneira descontrolada, o que torna a organização mais morosa. Entretanto, a estratégia de gestão se resume a replicar os documentos em dispositivos de armazenamento com vistas à preservação.

Bass (2013, p. 60) afirma que, embora os estudos de PIM classifiquem de maneira diferente os comportamentos dos usuários, existem alguns atributos que se sobressaem:

Em primeiro lugar, os itens digitais pessoais são ativos ou dormentes, com o primeiro logicamente situado para reencontros regulares e estes últimos relegados para locais mais obscuros. Como os itens digitais ativos inevitavelmente ficarão inativos, as aglomerações de arquivos dormentes são vítimas de uma "pobreza de atenção", competindo contra uma quantidade crescente de informação ativa para o processamento cognitivo. Em segundo lugar, o processo de busca de itens digitais pessoais depende invariavelmente da execução de consultas baseadas em atributos de palavras-chave recuperadas a partir da memória humana (sistema baseado em pesquisa) ou de pistas contextuais e espaciais encontradas através da navegação (sistema baseado em localização). Ambas as abordagens, no entanto, estão sobrecarregadas pela capacidade de um indivíduo para recuperar informações detaIhadas precisas a partir dos limites da memória humana, ou a capacidade de um indivíduo para manter proficientes e persistentes esquemas organizacionais dentro de estruturas de pastas hierárquicas. Em terceiro lugar, em todas as estratégias de manutenção de registros analisadas [...] há pouca menção a indivíduos eliminando conscientemente itens digitais, o que implica que os itens adormecidos são, por padrão, segregados de novos itens e mantidos para posterior processamento cognitivo e não eliminados por seus produtores. Em ambientes digitais, a retenção é a norma e a eliminação da exceção pela simples razão de que muitas vezes não há motivo para eliminar arquivos quando os limites no espaço virtual e no custo financeiro deixam de ser determinantes. (BASS, 2013, p. 60, tradução nossa).

Nesse sentido, à medida que a capacidade de armazenamento dos recursos tecnológicos aumenta, o acúmulo de todos os documentos sem práticas de avaliação emerge na maioria das pesquisas na área de PIM como um dos hábitos mais recorrentes entre os usuários. Na próxima seção são abordadas as noções de valor identificadas nos estudos de PIM.

\section{NOÇÕES DE VALOR EM ARQUIVOS PESSOAIS}

Desde Cunningham (1994, p. 101), a necessidade de avaliação é premente em arquivos pessoais digitais por conta da obsolescência tecnológica, uma vez que os suportes costumam ter vida útil curta. Além disso, a facilidade de acumular e o barateamento dos dispo- 
sitivos de armazenamento tendem a desestimular a prática de avaliação. Para Marshall, Bly e Brun-Cottan (2006, p. 3), na prática de manter todos os documentos digitais, documentos valiosos podem ser esquecidos "em meio à escória digital". Nesse sentido, a abordagem da avaliação de arquivos pessoais digitais tem aparecido atrelada à intervenção na pré-custódia e contempla dois aspectos. Um diz respeito à detecção de potenciais doadores para que sejam abordados o mais cedo possível "após tornar-se claro a partir de suas realizações e atividades que seus documentos são dignos de preservação" (CUNNINGHAM, 1994, p. 101, tradução nossa). Uma vez identificados os doadores cuja produção se alinha à política de aquisição da instituição, o outro aspecto relaciona-se à identificação dos documentos dignos de preservação permanente.

As objeções a esses aspectos já foram abordadas na seção sobre intervenção na précustódia. Entretanto, Cox (1996, p. 56) afirma que esse modelo de avaliação é problemático, a menos que seja conduzido no contexto de estratégias avaliativas que incidam sobre macro-questões. $O$ autor sugere um deslocamento da ênfase na coleta para a avaliação. A coleta centra-se, na maioria das vezes, em materiais considerados interessantes e valiosos a partir de um exame de como se apresentam e não por objetivos de avaliação mais amplos. Para Cox (1996, p. 56), aspectos políticos e psicológicos evidentes não têm sido estudados no cenário arquivístico. Se o que orienta a avaliação em arquivos institucionais são os valores probatório, administrativo, legal, entre outros, o que orientaria a avaliação em arquivos pessoais? Segundo Paquet (2000, p. 73, tradução nossa),

\footnotetext{
Os acervos pessoais de indivíduos contêm vários tipos de documentos: aqueles que nos dizem quem eles são: a sua educação; trabalho; suas atividades financeiras, familiares, sociais, culturais e recreativas; documentos legais e oficiais; documentos pessoais; várias lembranças, etc. Meu objetivo quando visito um doador em casa ou onde os documentos são criados é escolher o maior número possível de registros históricos para cobrir a diversidade das atividades do doador, suas raízes sociais, culturais ou econômicas, ou suas relações sociais e pensamentos políticos. Correspondência geral e pessoal produzida pelo indivíduo é, sem dúvida, um dos documentos de significado arquivístico substancial para selecionar. Documentos como jornais pessoais e correspondência fornecem informações sobre a pessoa e suas atividades e podem lançar luz sobre as atitudes de uma classe social ou segmento da sociedade à qual a pessoa pertence. Durante a visita para adquirir os documentos de um indivíduo, é importante ter uma idéia da natureza e quantidade de documentos relativos à sua carreira profissional.
}

Segundo Marshall (2008a), os indivíduos têm dificuldade de declarar, admitir ou prever o valor de seus documentos digitais. $O$ valor é medido muito mais pela replicação dos documentos do que pela declaração explícita de valor por meio da seleção. A autora afirma ainda que "o valor dos itens digitais é matizado e depende de muitos fatores, fatores que podem ser semelhantes às preocupações que temos quando arquivamos informalmente nossos importantes pertences físicos, mas ampliados pela quantidade de material." (MARSHALL, 2008a, tradução nossa).

A quantidade de acesso, de cópias, o envio para si, o cuidado na nomeação dos arquivos e o compartilhamento dos documentos podem demonstrar o valor do material (MARSHALL, 2008a). O número de versões, que sinalizam trabalho e criatividade empregados na produção do documento, bem como a proveniência dos documentos também são elementos que permitem algum grau de inferência sobre o valor dos documentos para o produtor em um arquivo pessoal. 
Sendo assim, Marshall (2008b) elenca alguns indicadores que têm relação com o valor de um documento: a fonte, que diz respeito à proveniência e à possibilidade de ser substituído ou não, a que custo e quanto de carga emocional carrega; as ações, que dizem respeito à visualização, manipulação ou modificação do documento, e se relacionam ao esforço criativo na elaboração do documento; e, por fim, a disposição, que diz respeito à maneira e ao local em que o documento foi armazenado e com quem foi compartilhado.

Para Marshall (2008b), existem elementos a partir dos quais os indicadores de valor devem ser notados: contexto, acréscimo de valor e metadados intrínsecos. De acordo com o contexto, é possível observar indícios para discernir entre documentos que são valiosos e documentos que simplesmente se acumularam. O acréscimo de valor está para os documentos que não aparentam ser valiosos no início, mas que com o passar do tempo são acionados, modificados, regravados ou compartilhados, e, com isso, são elevados à outra categoria de valor ou vice-versa. Os metadados intrínsecos são fundamentais para que a seleção não dependa da avaliação explícita de valor de um documento por parte do indivíduo. Os metadados intrínsecos podem ser automaticamente coletados com base nas propriedades do arquivo, em que pelos metadados intrínsecos torna-se possível verificar o número de vezes que o documento foi salvo e o tempo gasto na edição dos documentos.

Ao refletir sobre as razões para o arquivamento de documentos pessoais digitais, Dimitri $(2014$, p. 2) aponta que os documentos são arquivados por documentar a vida pessoal e profissional do indivíduo, por obrigações legais, por interesses pessoais, por valor sentimental e criativo. Para Whittaker e Hirschberg (apud BASS, 2013, p. 63), o arquivamento obedece a cinco critérios gerais: "valor de referência, valor jurídico e administrativo, disponibilidade imediata, lembrete de informações encontradas e desconfiança no armazenamento externo de informações." Mas,

\footnotetext{
Além de razões funcionais, as pessoas descreveram razões emocionais ou sentimentais para manter informações. Estes incluíram revisões de seu primeiro artigo publicado e especificações para projetos de pesquisa bem sucedidos. As pessoas admitem que essas informações têm pouca relevância para as prováveis atividades futuras, mas elas ainda não podem se separar dela, porque faz parte de sua história intelectual. (WHITTAKER; HIRSCHBERG, 2001, p. 7, tradução nossa).
}

Entretanto, para além de expor sentimentos através de lembranças por direito próprio, os participantes da pesquisa sobre as razões de arquivamento pessoal realizada por Kirk e Sellen (2008, p. 5) elencaram valores fundamentais que sustentam a razão pela qual os documentos são mantidos: construção da persona, conexão com um passado compartiIhado, para preservar um legado e em honra ao passado. Com resultado próximo, o estudo realizado por Kaye et al. (2008, p. 2-4) revela que os sujeitos arquivam por várias razões e de muitas maneiras e que as razões vão determinar o modo como os documentos são organizados. A primeira das razões é para uso posterior, a segunda para construção de um legado, a terceira para compartilhar recursos e a última é pelo medo da perda.

O projeto Digital Lives apontou em estudo (JOHN et al., 2010, p. 44) três explicações mais proeminentes oferecidas para o arquivamento de documentos digitais: para testemunhar a criatividade, para a memória sentimental e pessoal e para referência futura. Outras razões identificadas foram: para compartilhar com colegas, como registro de atividades e eventos passados e para deixar para sucessores ou para a posteridade. Para Bass $(2013, p$. 67), a pesquisa em PIM identifica muito dos mesmos valores atribuídos aos documentos pessoais e serve para complementar e reforçar os valores já estabelecidos. $O$ autor apresen- 
ta, a partir dos estudos de PIM e com base nas discussões sobre valores dos arquivos pessoais na literatura arquivística, um levantamento de valores, conforme Quadro 1.

Quadro 1 - Levantamento de valores para arquivos pessoais

\section{Identificações de valor PIM}

Valor identitário: itens envolvidos na construção contínua e expressão do eu.

Valor de memória pessoal: itens que facilitam reencontros com o passado pessoal.

Valor histórico pessoal e familiar: itens que registram narrativas individuais e compartilhadas.

Valor emocional e sentimental: itens que testemunham criatividade e realização, e provocam emoção.

Valor funcional: itens que servem como referência ou utilidade administrativa no dia-a-dia.

Valor de posteridade e legado: itens que perpetuam uma concepção de vida ou carreira para consideração externa.

Identificações de valores arquivísticos

Valor evidencial (probatório): documentos que registram funções, atividades e transações de pessoas.

Valor informacional: documentos que fornecem informações sobre pessoas significativas e de uso potencial para pesquisa histórica e sociológica.

Valor narrativo: documentos envolvidos no processo de contar histórias e autobiografia.

Valor social e cultural: documentos que registram o caráter contemporâneo, a personalidade, a intimidade, as crenças e a espiritualidade dos indivíduos dentro da sociedade.

Fonte: Bass (2013, p. 67).

Porém, no âmbito dos arquivos pessoais os valores não possuem fronteiras tão definidas. Nesse sentido, seja pelo titular ou por seus legatários, faz-se necessário que a avaliação seja pautada na atividade que o documento media, para que, assim, sua atuação, sua trajetória e seus interesses sejam evidenciados.

Se por um lado a avaliação de documentos institucionais, especialmente os de natureza pública, têm sido amplamente discutidas na literatura arquivística, o mesmo não ocorre no âmbito dos arquivos pessoais. Entretanto, com a inscrição da tecnologia digital na produção de arquivos pessoais, o tema não pode ser negligenciado, sob pena de não restar nada ou restar um todo que não revela o suficiente para a compreensão das funções dos indivíduos na sociedade. Desse modo, a identificação de valores é imprescindível para determinar o que e como os documentos serão preservados.

\section{PRÁTICAS DE PRESERVAÇÃO DIGITAL EM ARQUIVOS PESSOAIS}

Quando avaliados e selecionados, o uso dos documentos se amplia e a sua preservação a longo prazo se torna necessária. A preservação digital consiste em uma série de eventos dinâmicos e contínuos e, portanto, depende de um compromisso regular que começa com o produtor e se estende aos arquivistas. A literatura sobre arquivos pessoais digitais revela que, na maioria dos casos, a preservação se resume à prática de replicação de todos os documentos, sem avaliação, em diversos dispositivos de armazenamento. Entretanto, a preservação de arquivos pessoais digitais tem sido a maior preocupação das instituições de 
custódia, que têm buscado orientar os indivíduos acerca da preservação de seus documen$\operatorname{tos}^{3}$.

Marshall (2008a) identificou alguns métodos de preservação de arquivos pessoais digitais. Os indivíduos pensam em backup do sistema como a mesma coisa que um arquivo de longo prazo; adotam uma sucessão de pastas "Meus documentos" como uma coleção de arquivos que é armazenada no computador de uso corrente; transferem arquivos importantes para mídias de armazenamento externo, como $C D$ s e $D V D s$, ou ainda disquetes, como utilizou o escritor Rodrigo de Souza Leão ${ }^{4}$; usam uma conta de e-mail gratuita em conjunto com uma dinâmica de anexos para criar um arquivo; utilizam uma combinação de sites de mídia social como recurso para armazenar fotos e vídeos; e mantêm toda a plataforma - o computador, seus periféricos e programas - quando adquirem uma nova, para serem reinicializados e acessados quando os arquivos são necessários. Segundo Voutssas Márquez (2013, p. 13-14, tradução nossa),

Os requisitos para a preservação a longo prazo levam ao limite as tecnologias atuais de informação e gestão da informação. Do ponto de vista das organizações, preservar suas informações digitais a longo prazo requer sistemas, modelos técnicos e organizacionais, bem como pessoal qualificado e experiente, robustos o suficiente para superar as falhas tecnológicas, mudanças sucessivas de plataformas de computação, obsolescência de meios e formatos de armazenamento, erro humano, negligência e ataques maliciosos, alterações na missão institucional das organizações ou falhas e interrupções em sua direção e financiamento, para citar algumas ameaças.

Para Voutssas Márquez (2009, p. XVI-XIX), os seguintes fatores incidem sobre a preservação de arquivos digitais: culturais, tecnológicos, legais, documentais, econômicos e sociais. Entretanto, segundo material produzido pela Library of Congress (2010), os indivíduos que desejam preservar seus documentos digitais podem obedecer à mesma estratégia para todo tipo de arquivo digital: primeiro, identificar o que se deseja guardar, disso advém a importância da avaliação; segundo, decidir o que é mais importante; terceiro, organizar o conteúdo; e quarto, guardar cópias em lugares distintos. Bass (2013, p. 68) questiona a simplicidade das práticas propostas pela Library of Congress para apresentar a preservação digital local, em que o usuário tem domínio sobre os suportes físicos (hardwares) e lógicos (softwares), e a preservação digital on-line, estabelecida numa relação cliente-serviço em que os documentos são armazenados numa infraestrutura de servidor que o usuário não possui e não controla.

Nesse sentido, a partir da perspectiva de cadeia de preservação, qual seja "o sistema de controle que se estende ao longo de todo o ciclo de vida dos registros, a fim de garantir a sua identidade e integridade ao longo do tempo" (DURANTI; PRESTON, 2008, p. 777, tradução nossa), o Projeto InterPARES elaborou, no contexto de sua segunda fase, dois conjuntos de diretrizes - baseadas no estudo de casos reais - para produção, manutenção e preserva-

\footnotetext{
3 Library of Congress (http://digitalpreservation.gov/personalarchiving/), Universities of Oxford and Manchester (http://www.paradigm.ac.uk/), Arxiu Municipal de Girona (http://www.girona.cat/sgdap/docs/dia2013 def.esp.pdf), InterPARES (http://www.interpares.org/ip2/display file.cfm?doc=ip2 preserver guidelines booklet--portuguese.pdf), Universidad Nacional Autónoma de México (http://132.248.242.3/ publica/archivos/libros/como_preservar_patrimonio_dig_pers.pdf.).

4 "Nunca fiz nada que não tivesse uma cópia de segurança em papel e outra eletrônica. Tudo por paranoia de perder tudo que tenho dentro do computador. É que sou um escritor e guardo todo o meu tesouro - que são meus escritos - dentro dessa máquina pouco confiável." (LEÃO, 2003, p. 1).
} 
ção de registros a longo prazo: um conjunto para indivíduos que criam documentos digitais, como artistas, cientistas, profissionais e pesquisadores, e outro conjunto para preservadores de documentos.

No primeiro conjunto de diretrizes o objetivo é ajudar os indivíduos a tomar decisões conscientes a respeito de como produzir e manter os documentos, com a finalidade de assegurar sua preservação pelo tempo necessário. O cumprimento das diretrizes tende a ajudar a assegurar o acesso aos documentos que merecem ser preservados por um longo período em um repositório arquivístico quando estes forem recolhidos aos cuidados de uma instituição arquivística (INTERPARES, 2013a, p. 2).

O conjunto destinado ao produtor de documentos possui dez diretrizes: seleção de hardwares, softwares e formatos de arquivo que ofereçam as melhores expectativas de garantia de que os materiais digitais permanecerão facilmente acessíveis ao longo do tempo; certificação de que os materiais digitais mantidos como documentos arquivísticos são estáveis e fixos tanto no conteúdo quanto na forma; certificação de que os materiais digitais estão identificados adequadamente; certificação de que os materiais digitais carregam informações que ajudarão a verificar sua integridade; agrupamento dos materiais digitais de forma lógica; utilização de técnicas de autenticação que favoreçam a manutenção e a preservação dos materiais digitais; proteção dos materiais digitais de ações não autorizadas; proteção dos materiais digitais de perdas acidentais e corrupção; prevenção contra a obsolescência de softwares e hardwares; e consideração dos aspectos relacionados à preservação em longo prazo (INTERPARES, 2013a, p. 4-16).

O segundo conjunto de diretrizes destinado ao preservador tem o objetivo de atender à demanda de preservação de instituições ou de programas cujos documentos arquivísticos têm que ser armazenados e acessados durante longos períodos, bem como à demanda das instituições arquivísticas responsáveis pela preservação a longo prazo de documentos arquivísticos recolhidos e pela manutenção de sua acessibilidade ao público (INTERPARES, 2013b, p. 2). Esse conjunto possui cinco diretrizes: gerenciamento da estrutura da cadeia de preservação; avaliação de documentos para preservação permanente; recebimento de documentos arquivísticos selecionados para preservação permanente; preservação dos documentos recebidos; e garantia de acesso aos documentos. Segundo o projeto, as estratégias de preservação são duas: uso de padrões (restrição de formatos a serem geridos, conversão, etc.) e dependência tecnológica (preservação da tecnologia, reengenharia de software, emulação, etc.) (INTERPARES, 2013b, p. 4-23).

\section{CONSIDERAÇÕES FINAIS}

Os documentos são cobertos durante toda a sua existência e, assim, têm acessibilidade e legibilidade garantidas ao longo do tempo, bem como a manutenção de forma, conteúdo e relações orgânicas, fundamentais para a credibilidade do documento enquanto documento de arquivo. Como já foi explorado, o tratamento de arquivos pessoais digitais deve ser empreendido a partir do conhecimento de toda trajetória do documento, desde sua gênese, passando por sua manutenção, sua avaliação, e sua preservação ao longo do tempo como documentos autênticos, capazes de evidenciar as atividades que o compõem. De acordo com o InterPARES (2013b, p. 2),

Todas as atividades para gerenciar os documentos, no curso de sua existência, estão ligadas, como em uma cadeia, e são interdependentes. Se um elo se rompe, a cadeia não pode executar sua função. Se certas atividades e ações não são realiza- 
das com os documentos, sua integridade (ou seja, suas confiabilidade e autenticidade) e sua preservação estão em risco.

Diante desse cenário, os estudos de PIM podem auxiliar no desenvolvimento metodológico para tratamento de arquivos pessoais. Ainda que sejam realizados sem um viés arquivístico, sob uma perspectiva mercadológica, na medida em que investigam o comportamento dos usuários de tecnologia para criação e manutenção de arquivos digitais, oferecem subsídios para que o tratamento desses arquivos seja considerado, especialmente no que diz respeito à identificação das práticas de preservação e dos critérios adotados pelos indivíduos na avaliação de documentos.

\section{REFERÊNCIAS}

BARREAU, D.; NARDI, B. A. Finding and reminding: file organization from the desktop. ACM Digital Library, New York, v. 27, n. 3, p. 39-43, jul. 1995. Disponível em:

http://dl.acm.org/citation.cfm?id=221307. Acesso em: 10 jun. 2016.

BASS, J. A PIM perspective: leveraging personal information management research in the archiving of personal digital records. Archivaria, Ottawa: ACA, n. 75, p. 49-76, 2013.

BOARDMAN, R. SASSE, M. A. Stuff goes into the computer and doesn't come out: a cross-tool study of personal information management. [S.I: s.n], 2004. Disponível em:

http://www.richardboardman.com/docs/boardman-chi04.pdf. Acesso em: 11 jun. 2017.

COX, R.J. The Record in the Manuscript Collection. Archives and Manuscripts, v. 24, n. 1, p. 46-61, 1996.

CUNNINGHAM, A. The archival management of personal records in electronic form: some suggestions. Archives and Manuscripts, v. 22, n. 1, p. 94-105, 1994.

DIMITRI, J. Les bonnes pratiques de gestion des archives personnelles à l'ère numérique. [Trabalho de pesquisa], Université de Montréal, dez. 2014. Disponível em:

https://papyrus.bib.umontreal.ca/xmlui/bitstream/handle/1866/11361/Dimitri-J-archivesperso.pdf?sequence=1. Acesso em: 11 jun. 2017.

DURANTI, L.; PRESTON, R. International research on permanent authentic records in electronic systems (InterPARES) 2: experiential, interactive and dynamic records. Padova: Associazione Nazionale Archivistica Italiana, 2008.

HUMAN FACTORS IN COMPUTING SYSTEMS (CHI 96), Vancouver, 13-18 abr.1996. Disponível em: https://pdfs.semanticscholar.org/5251/b6170ac80da4b6f6dbb3dcb542985d217e8f.pdf. Acesso em: 11 jun. 2017.

INTERPARES 2 PROJECT. Diretrizes do preservador: a preservação de documentos arquivísticos digitais: diretrizes para organizações. Tradução: Arquivo Nacional e Câmara dos Deputados, 2013b.

INTERPARES 2 PROJECT. Diretrizes do produtor: a elaboração e a manutenção de materiais digitais: diretrizes para indivíduos. Tradução: Arquivo Nacional e Câmara dos Deputados, 2013a.

JOHN, J. L. et al. Digital lives: personal digital archives for the 21st Century, Version 2, [S.I: s.n], 2010. 
KAYE, J. et al. To have and to hold: exploring the personal archive. In: PROCEEDINGS OF THE SIGCHI CONFERENCE ON HUMAN FACTORS IN COMPUTING SYSTEMS, 2008. p. 1-10.

KIRK, D.; SELLEN, A. On Human Remains: Excavating the Home Archive. Microsoft Technical Report (Jun 2008), Disponível em: https://www.microsoft.com/en-us/research/wpcontent/uploads/2008/06/tr-2008-85.pdf. Acesso em 14 jan. 2020.

LANSDALE, M. W. The Psychology of Personal Information Management. Applied Ergonomics, v. 19, n. 1, p. 55-66, mar. 1988.

LEÃO, R. S. Backup. Rio de Janeiro, 2003. Crônica não publicada.

MACKAY, W. E. M. More than just a communication system: diversity in the use of electronic mail. In: PROCEEDINGS OF THE 1988 ACM CONFERENCE ON COMPUTER-SUPPORTED COOPERATIVE WORK, 1988 , p. 344-53.

MARSHALL, C. C. Rethinking personal digital archiving part 1: four challenges from the Field. D-Lib Magazine, 2008a.

MARSHALL, C. C. Rethinking personal digital archiving part 2: implications for services, applications, and institutions. D-Lib Magazine, 2008b.

MARSHALL, C. C.; BLY, S.; BRUN-COTTAN, F. The long term fate of our digital belongings: toward a service model for personal archives. Proceedings of IS\&T Archiving. Springfield: Society for Imaging Science and Technology, 2006. p. 25-30.

PAQUET, L. Appraisal, acquisition and control of personal electronic records: from myth to reality. Archives and Manuscripts, v. 28, n. 2, p. 71-91, 2000.

VOUTSSAS MÁRQUEZ, J.. Cómo preservar mi patrimonio digital personal. México: UNAM / IIBI, 2013.

VOUTSSÁS MÁRQUEZ, J. Preservación del patrimonio documental digital en México. UNAM, Centro Universitario de Investigaciones Bibliotecológicas, 2009.

WHITTAKER, S.; SIDNER, C. Email overload: exploring personal information management of email. In: PROCEEDINGS OF THE CONFERENCE ON HUMAN FACTORS IN COMPUTING SYSTEMS (CHI 96), Vancouver, 13-18 abr.1996 